\title{
Development of Energy Saving Power Steering
}

\author{
Fumihide KOZUMA*, Tsunefumi ARITA** and Hisashi TSUDA*** \\ * Basic Technology Research and Development Center \\ KAYABA Industry Co., Ltd. \\ 1-12-1 Asamizodai, Sagamihara, Kanagawa, 228-0828 Japan \\ (E-mail: kouzuma-fum@kyb.co.jp) \\ ** Steering Engineering Department, Gifu North Plant \\ KAYABA Industry Co., Ltd. \\ 2548 Dota, Kani, Gifu, 509-0298 Japan \\ *** Steering Engineering Department, Europe Branch \\ KAYABA Industry Co., Ltd. \\ Kimpler strasse. 336, 47807 Krefeld, Germany
}

\begin{abstract}
This paper shows the energy saving power steering system, which was named as KEEPS (Kayaba Electronic Controlled Energy Saving Power Steering). In a conventional hydraulic power steering system, the hydraulic pump always supplies enough quantity of oil to the hydraulic circuit. This extra oil flow increases driving torque of the pump, thus the hydraulic power steering system wastes energy. On the other hand, KEEPS can control oil flow electrically in accordance with the condition of a vehicle. In the measurement test for energy consumption of the power steering system with the actual vehicle on test courses, KEEPS got $48 \%$ less at city mode, $41 \%$ less at highway mode and $39 \%$ less at country mode compared with the conventional hydraulic steering system.
\end{abstract}

\section{KEY WORDS}

KEEPS, Hydraulic Power Steering, Energy Saving, Electronic Control

\section{INTRODUCTION}

Recently under international environmental problems, saving fuel consumption of an automobile has been required, and the various regulations of fuel consumption have been implemented. These activities of reducing fuel consumption influence on not only engines but also automotive equipments, and high efficiency equipments are required. This situation applies to a hydraulic power steering system too.

In a conventional hydraulic power steering system, the hydraulic pump always supplies enough quantity of oil to the hydraulic circuit. The circuit has hydraulic resistances such as the steering gear and the hose, thus extra oil flow increases pressure loss in the circuit and driving torque of the pump. As a result, unnecessary energy is consumed. And to improve the energy problem of power steering systems, various systems have been proposed. Those are variable displacement pump, EHPS (Electronic Hydraulic Power Steering), EPS (Electric Power Steering) and so on. The purpose of this paper is to confirm effect of energy saving by the newly developed power steering system.

\section{CONCEPT OF ENERGY SAVING}

Figure 1 is one experimental result concerning to the steering occurrence rate at various driving modes. In the city and the highway mode, about $80 \%$ of the steering occurrence angle is less than 5 degree. In the country mode, under 5 degree steering angle occupies about $50 \%$ 
of all.

Figure 2 shows the relationship among driving torque and flow rate of a hydraulic power steering pump at constant pump speed. When flow rate goes to lower, pressure loss in the circuit and driving torque of the pump are decreased.

Therefore it is possible to reduce energy consumption of a hydraulic power steering system, if pressure loss and driving torque can be reduced by minimizing oil flow rate supplied from the pump into the hydraulic circuit in
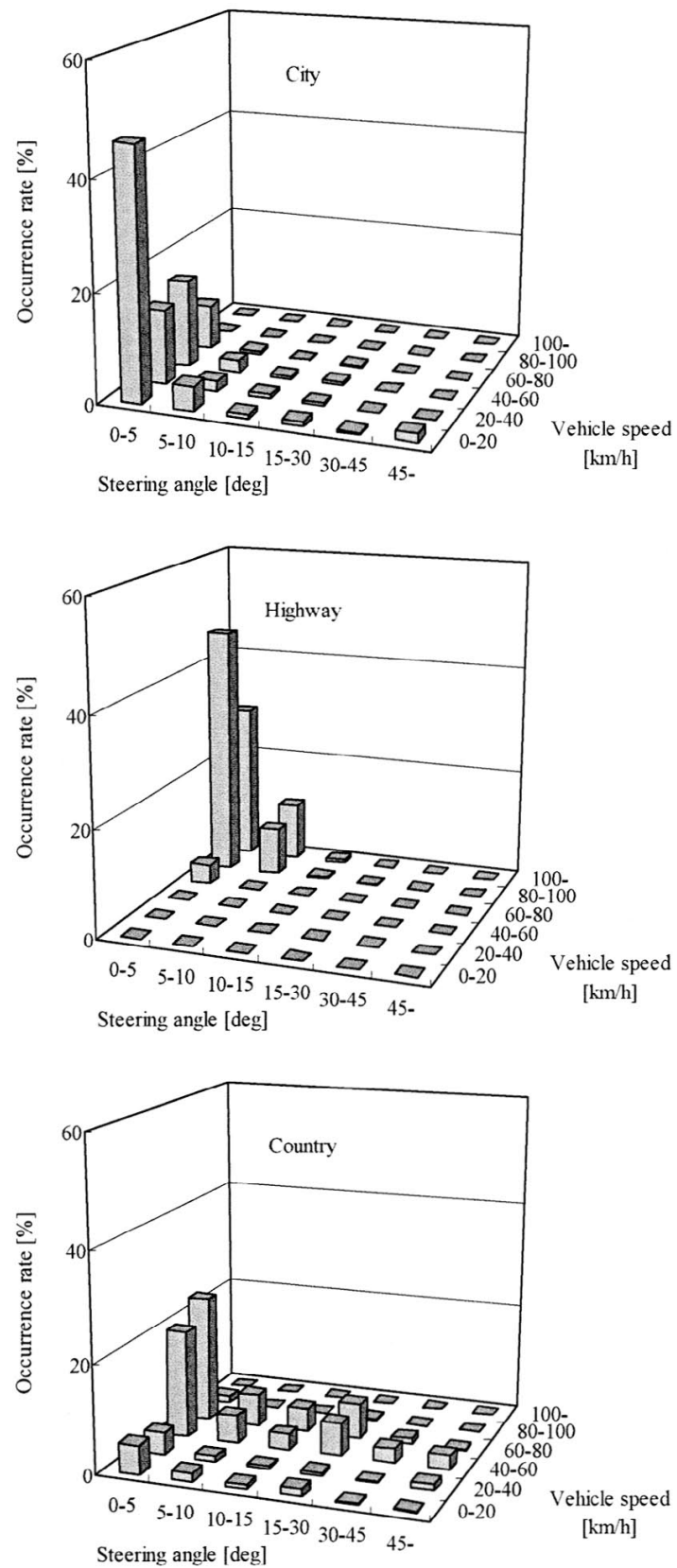

Figure 1 Steering occurrence rate non-steering or no power assist mode.

\section{SYSTEM CONFIGURATION}

As shown in Figure 3, the system of KEEPS mainly consists of a pump assembly, a power steering gear and an electronic control unit (ECU). The pump and the steering gear are used as same as a conventional hydraulic power steering one. A proportional solenoid valve is adopted instead of a flow control valve in the pump assembly. ECU and sensors are newly adopted. Electric current that is defined by ECU controls oil flow rate.

In non-steering or no power assist mode, ECU orders the solenoid valve to close its flow area. Then by-pass flow rate is increased, and main flow rate is decreased approximately to $15 \%$ of normal one. Hereby load pressure of the pump is kept lower level and driving torque of the pump is also reduced. Figure 4 shows the comparison of pump driving torque at non-steering mode between a conventional power steering and KEEPS. On the other hand when a driver steers, ECU orders the

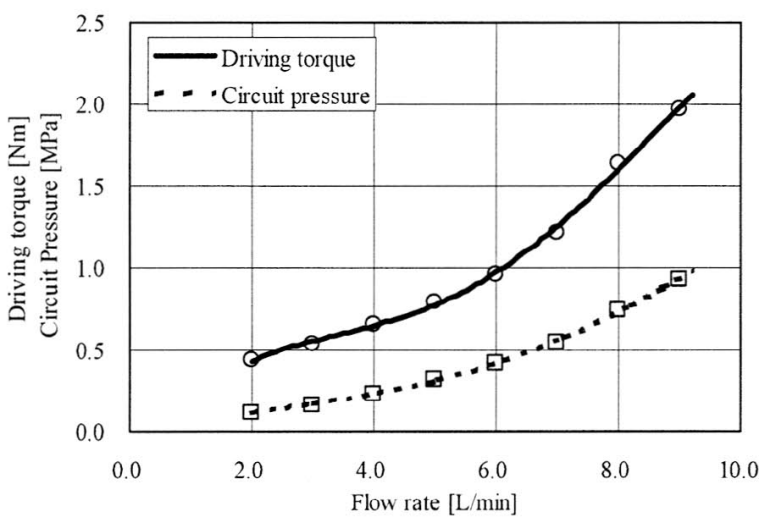

Figure 2 Pump driving torque

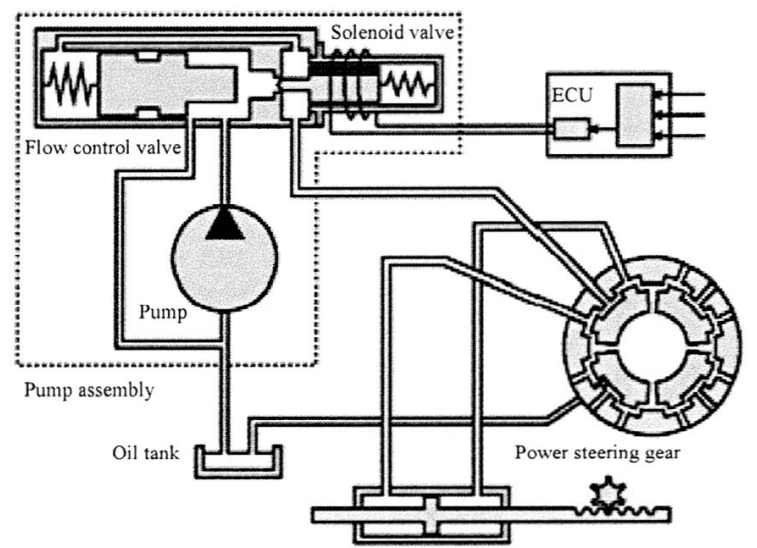

Figure 3 System configuration 
solenoid valve to open its flow area and main flow rate is returned quickly to necessary quantity.

Thus ECU controls main flow rate according to vehicle condition, KEEPS can realize energy saving and suitable steering feeling at the same time [1].

\section{EXPERIMENTAL TESTS}

We have practiced various tests to check the effects of energy saving by KEEPS. Below results were obtained using by the conventional hydraulic power steering system and KEEPS that were designed for the $2000 \mathrm{cc}$-class passenger car.

\section{Power consumption test on bench tester}

This test is measurement of power consumption on a power steering bench tester using similar hydraulic circuit of an actual vehicle, and was executed in a European university. The bench tester can reproduce various driving conditions, to give pump speed and load force to steering gear. At the same time the bench tester can provide other information, for example vehicle speed and steering angle, which are necessary to KEEPS ECU. Power consumption

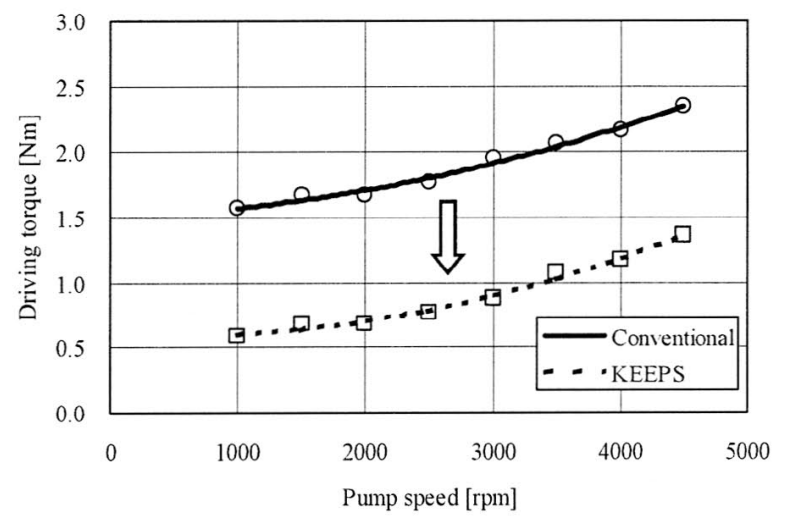

Figure 4 Comparison of driving torque

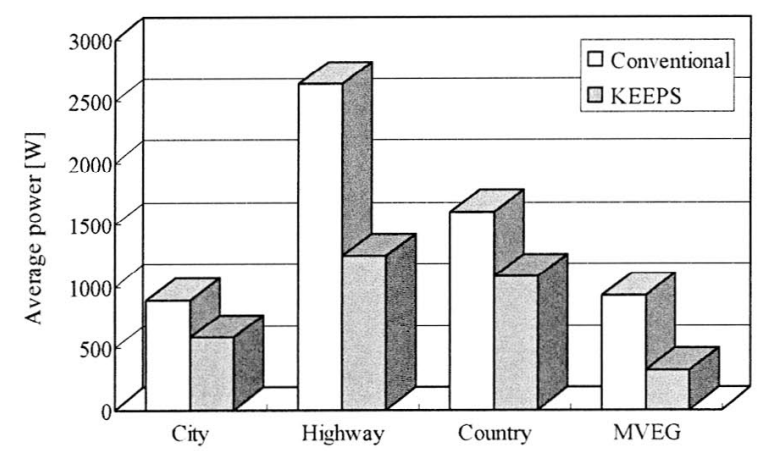

Figure 5 Result of power consumption test of the power steering system is calculated from pump speed and driving torque measured directly.

In this test, KEEPS reduced power consumption by $34 \%$ at city mode, $53 \%$ at highway mode, $32 \%$ at country mode and $66 \%$ at MVEG mode test as shown in Figure 5 . In these test modes, only MVEG is under non-steering condition.

\section{Fuel consumption test using actual car}

This test is investigation of fuel consumption efficiency using an actual car on a chassis dynamometer, and was executed in a Japanese institute. The test on the chassis dynamometer is carried out under non-steering mode. The chassis dynamometer provides the vehicle running resistance according to vehicle speed. During under testing, environment of the vehicle such as temperature
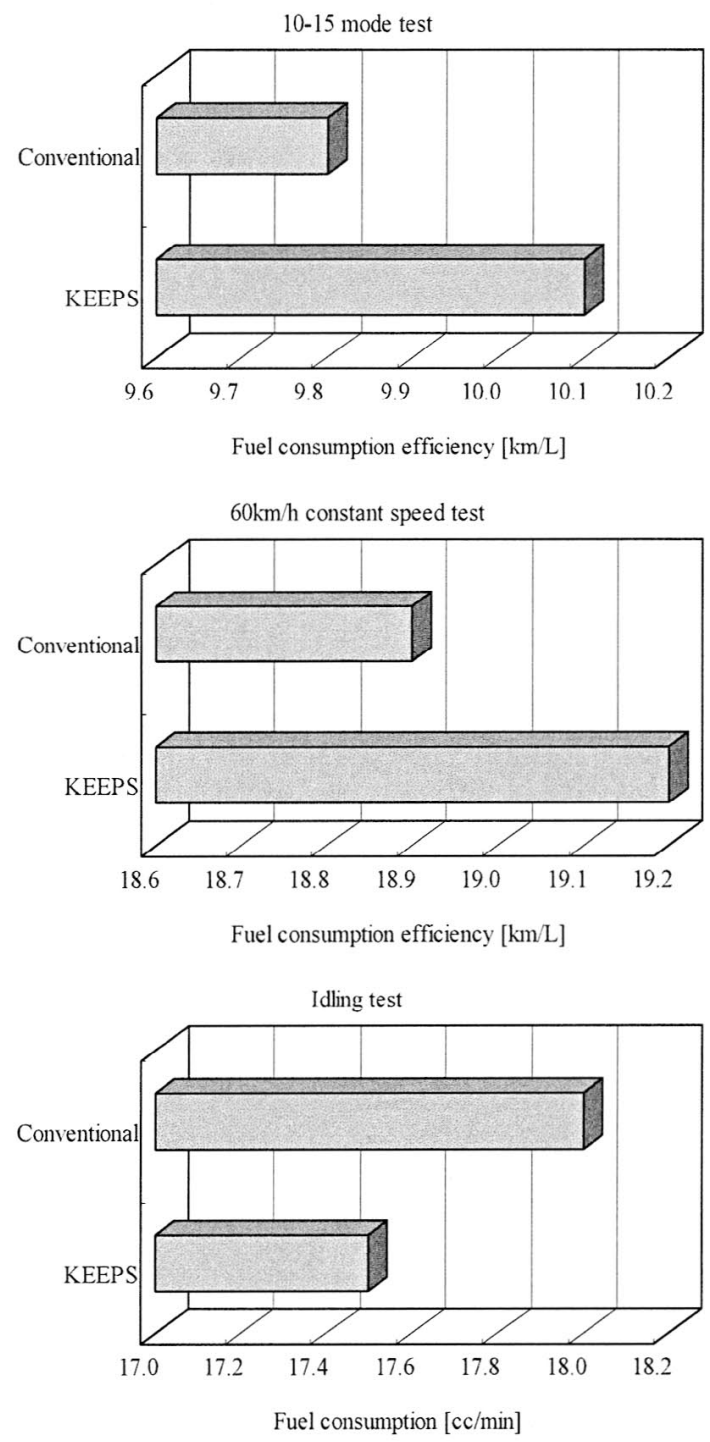

Figure 6 Result of fuel consumption test 
and humidity is controlled steadily. Fuel consumption is measured from emission gas by carbon balance method. In this test as shown in Figure 6, KEEPS car got 3.1\% improvement of fuel consumption at 10-15 mode test, $1.6 \%$ improvement at $60 \mathrm{~km} / \mathrm{h}$ constant speed test and $3.1 \%$ improvement at idling test.
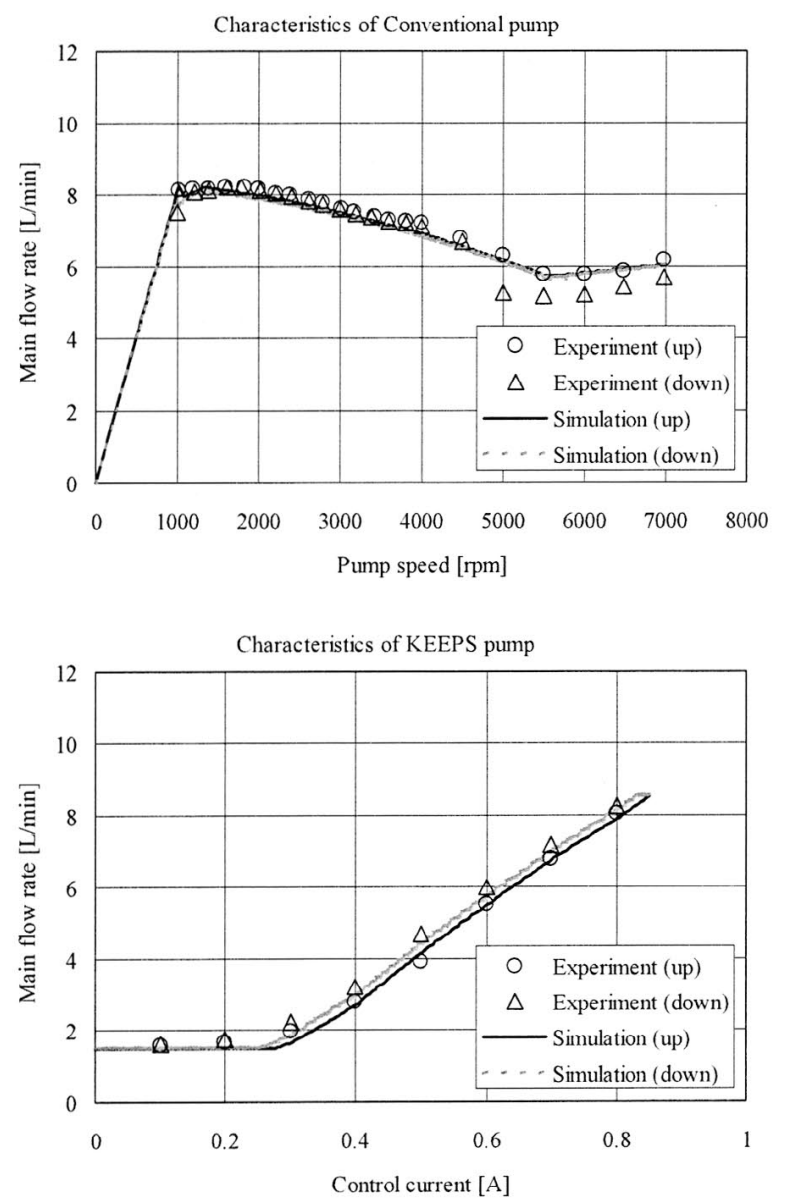

Figure 7 Flow rate characteristics of the pumps

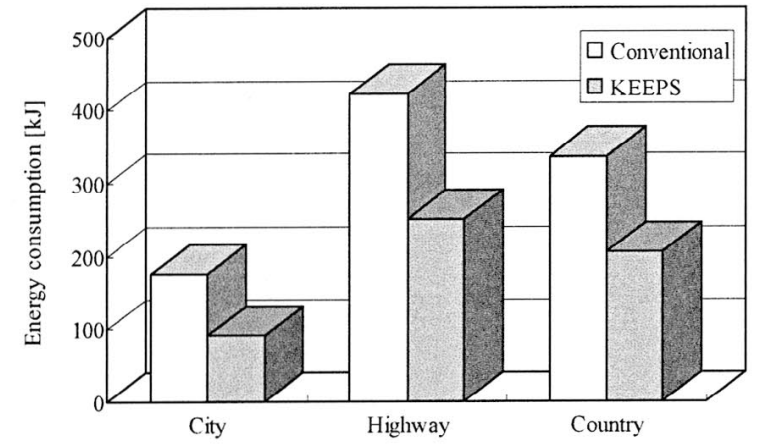

Figure 8 Comparison of energy consumption test results

\section{Energy consumption test on test course}

This test is estimation of energy consumption of power steering system, and was executed on test courses with an actual vehicle. Generally it is difficult to measure driving torque of a hydraulic power steering pump on a vehicle. Therefore we measured the mechanical efficiency of the pump before testing, and calculated driving torque, power and energy consumption from vehicle condition such as pump speed and circuit pressure.

On the other hand it is impossible to test or compare for various samples under the strictly same condition of a vehicle. To solve an above problem, we made the simulation program of the hydraulic power steering system. This program consists of mathematical models of a pump assembly, a power steering gear, hoses and ECU (KEEPS). Above elements are considered to dynamics and nonlinear characteristics, and the program can simulate behavior of the hydraulic power steering system to give condition around the system [2].

Figure 7 is the comparisons of the pump characteristics between experimental result and simulative one using the program.

In this test, KEEPS decreased energy consumption by $48 \%$ at city mode, $41 \%$ at highway mode and $39 \%$ at country mode as shown in Figure 8.

\section{CONCLUSION}

As above-mentioned, we confirmed effect of reduction of energy or fuel consumption by KEEPS. For example, in the measurement test for energy consumption of the power steering system with the actual vehicle on test courses, KEEPS got $48 \%$ less at city mode, $41 \%$ less at highway mode and $39 \%$ less at country mode compared with the conventional hydraulic steering system.

According to these result and rate of general driving mode [3], it is expected that KEEPS can decrease energy consumption of a hydraulic power steering by about $40-50 \%$.

We will continue to improve KEEPS more as energy saving technology of the hydraulic power steering system.

\section{REFERENCES}

1. Takai, M. and Tsuda, H., Electronic Controlled Energy Saving Hydraulic Power Steering 'KEEPS', Kayaba Technical Review, 2002, No.25, pp.34-37

2. Kozuma, F., Simulation of Electronic Controlled Energy Saving Hydraulic Power Steering, Kayaba Technical Review, 2005, No.30, pp.77-81

3. Kabuto, K., Murayoshi, K., and Hashizume, H., Energy Efficient Power Steering Technology, Journal of the Japan Hydraulics and Pneumatics Society, 1993, 24-6, pp.650-657 